DOI: http://dx.doi.org/10.4314/star.v4i2.18 ISSN: 2226-7522(Print) and 2305-3372 (Online) Science, Technology and Arts Research Journal Sci. Technol. Arts Res. J., April-June 2015, 4(2): 149-156 Journal Homepage: http://www.starjournal.org/

Original Research

\title{
Utilization of Early Infant Diagnosis of HIV Infection and Associated Factors in Western Ethiopia: Cross-sectional Study
}

\author{
Getahun Bayou ${ }^{1}$, Tariku Dejene $^{2}$, Lemessa Dube ${ }^{2}$, and Emiru Adeba ${ }^{3^{\star}}$ \\ ${ }^{1}$ ICAP, Columbia University, Post Box:5566, Addis Ababa, Ethiopia \\ ${ }^{2}$ Department of Epidemiology and Biostatistics, College of Public Health and Medical Sciences, \\ Jimma University, Post Box: 378, Jimma, Ethiopia \\ ${ }^{3}$ Department of Public Health, College of Health and Medical Sciences, Wollega University, \\ Post Box: 395, Nekemte, Ethiopia
}

\begin{tabular}{|c|c|}
\hline Abstract & Article Information \\
\hline 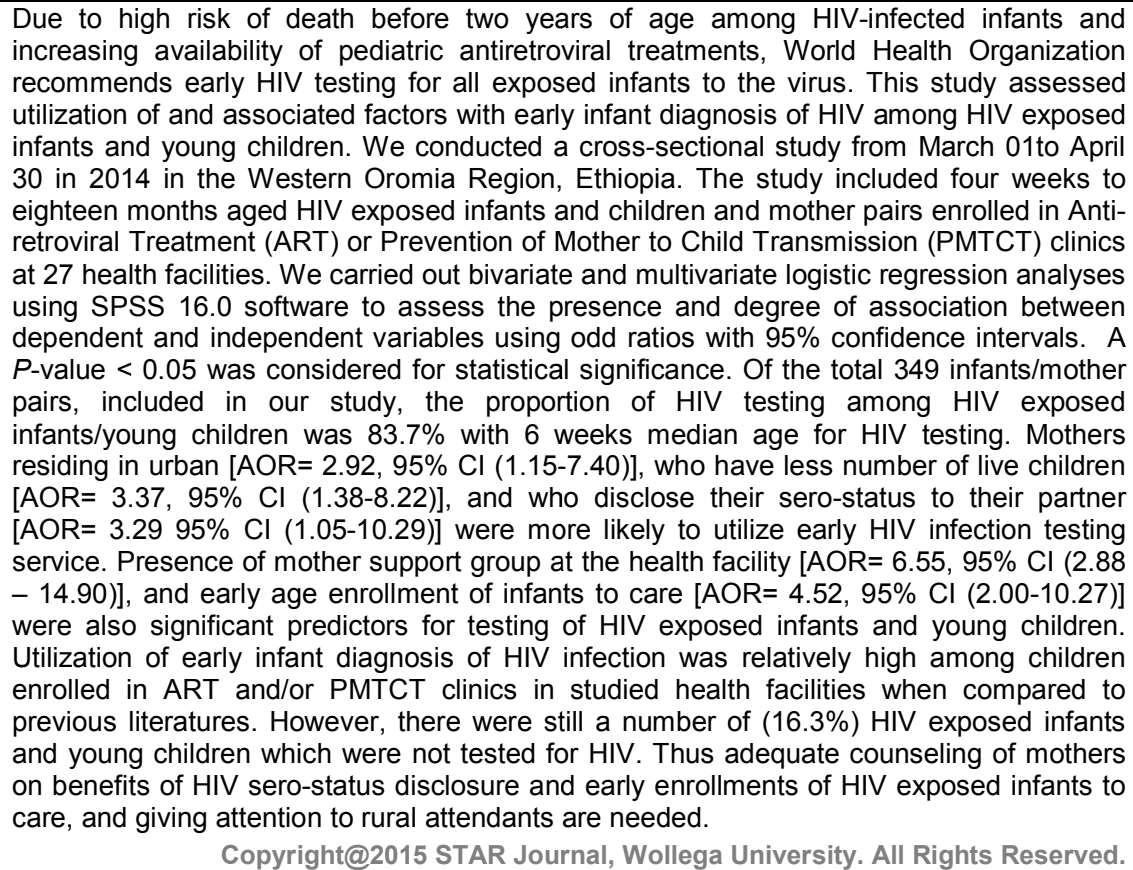 & 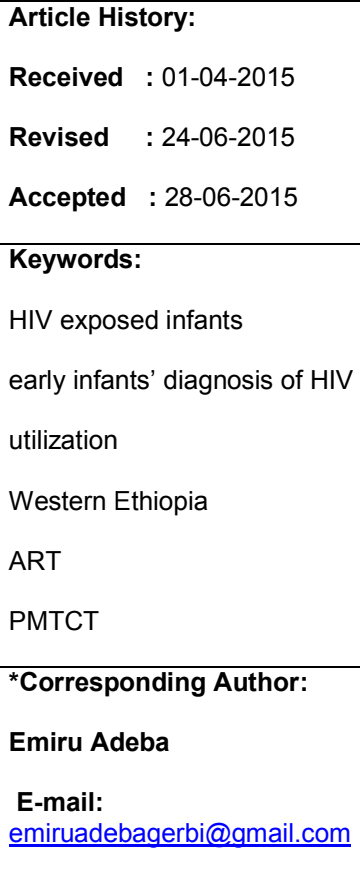 \\
\hline
\end{tabular}

\section{INTRODUCTION}

Early identification of infants infected with HIV followed by prompt ART treatment and appropriate management helps to reduce morbidity and mortality from HIV as it is progressing fast among pediatric age group. About one third and half of HIV infected infants die before their first and second year of birth, respectively, if not diagnosed and enrolled in to care (Joint United Nation Programme on HIV AIDS, 2013; WHO, 2010; UNAIDS, UNICEF, WHO, 2013).

All infants exposed to HIV should be tested, even if their mothers received Anti-retrovirals (ARVs) for Prevention of Mother to Child Transmission (PMTCT).
World Health Organization (WHO), in its guideline on provider initiated HIV testing, recommends early infant HIV diagnosis to be performed at an age of 6 weeks or any time subsequently initiated by the responsible health care providers (Federal HIVIAIDS Prevention and Control Office Federal Ministry of Health of Ethiopia, 2007; WHO, 2010; World Health Organization, 2010).

The WHO recommends immediate initiation of ART upon diagnosis of HIV infection in infants and young children, irrespective of their cell differentiation 4 plus $\left(\mathrm{CD}^{+}\right)$T-lymphocyte counts. Therefore, identification of all HIV exposed infants, early HIV testing, follow up for 
results, linkage of those found positives to treatment, growth monitoring, and final HIV status determination after complete weaning would ensure proper utilization of Early Infant Diagnosis (EID) for HIV exposed infants and young children (Federal HIVIAIDS Prevention and Control Office Federal Ministry of Health of Ethiopia, 2007; Fonjungo et al., 2013 ).

Serological assay HIV antibody detection which is suitable in adults cannot be reliably used for confirmatory HIV diagnosis among infants as the interpretation of positive HIV antibody testing is complicated due to maternal HIV antibody that can persist for some 18 months. Thus more suitable diagnostic testing methods (Deoxy ribose nucleic acid polymerase chain reaction (DNA-PCR) are required tests that depend on detection of HIV virus antigen (HIV DNA) in infants' blood whereby dry blood spot (DBS) can be used as a sample taking technique (Federal HIVIAIDS Prevention and Control Office Federal Ministry of Health of Ethiopia, 2007; WHO ,2010).

Even though early infant diagnosis is expanding in many countries overall testing for infants remain low. In resources limited settings, evidences showed several contributing factors for many challenges facing EID services uptake (UNAIDS, UNICEF, WHO, 2013). In 2012 , in low and middle income countries, only $39 \%$ of children born from known HIV positive women were estimated to access to HIV testing within the recommended two months of their birth (UNAIDS, UNICEF, WHO, 2013).

In Ethiopia, DNA PCR for EID of HIV was introduced in 2006 at a laboratory owned by the Ethiopian Health and Nutrition Research Institute (EHNRI) in Addis Ababa. A total of 2848 infants were tested from April 2006 to April 2008 at this central laboratory, it was the only with capability to perform EID, that resulted in $546(19.2 \%)$ positive samples. This method was then expanded to other regional laboratories in 2008. In 2010, an additional 16,985 HIV exposed infants were tested and of these 1, $915(11.3 \%)$ found positive, at all laboratories (where the service is available) in the country including that at EHNRI (Fonjungo et al., 2013).

However, in Ethiopia despite the service availability, it was not consistently utilized. The WHO-UNICEF joint report in 2013 estimated that only $19 \%$ of infants born from women living with HIVIAIDS were tested for HIV in 2012. As to Center for Disease Control (CDC) Ethiopian office report in 2012, 45\% of known HIV exposed infants were tested in DNA-PCR (UNAIDS, UNICEF, WHO, 2013; CDC Ethiopia, 2012).

Psychosocial, socio-demographic and health system factors need to be addressed for proper and sustained EID service utilization as they contribute for EID for HIV to improperly be utilized (Torpey et al., 2012). Thus, this study is therefore assessed utilization of early infant diagnosis of HIV infection service and factors affecting in Western Oromia Region, Ethiopia.

\section{METHODS AND MATERIALS}

\section{Study Design, Setting and Population}

We employed an institutional based cross-sectional quantitative study to collect data from 4 weeks to 18 months aged HIV exposed infants /young children and mother pairs enrolled in ART and/or PMTCT clinics from March 01, 2014 to April 30, 2014 at 27 health facilities. Facilities included were 7 hospitals and 20 health centers in four zones (East Wollega, Horo Guduru, West Wollega and Kelem Wollega) of West Oromia Region, Western Ethiopia. Total population of the study area is about 4.67 million, with estimated $1: 1$ sex ratio. These four zones have a total of 9 hospitals and 164 health centers.

In the area a total of 67 health facilities ( 9 hospitals and 58 health centers) were providing EID of HIV exposed infants' service. Here EID is done through DBS sampling technique whereby samples are referred to one referral regional laboratory performing DNA-PCR testing. The EID service provision was not uniformly initiated at all health facilities. It was started at all hospital in 2006, at some 37 health centers in 2010 and expanded to the rest of health centers in 2012.

During the study period there were about 400 exposed infants aged at birth to 18 months and enrolled in the service. Of all 67 health facilities providing EID service, 35 health facilities have no enrolled HIV exposed infants and 5 have very few (only 1 or 2) enrolled infants. Thus we included only 27 health facilities in the study.

\section{Sample Size, Recruitment and Selection of Subjects}

All infant-mother pairs having complete registers and follow-up cards from selected health facilities were included in the study. From register of health facilities 376 HIV-exposed infants and young children aged 4 weeks to 18 months were identified. Of these twenty-seven were excluded due to incomplete records resulting in a total sample size of $349 \mathrm{HEl}$ infant and young children - mother pairs for our study.

\section{Data Collection Tools and Measurements}

Data were collected by four data clerks, who were familiar and experienced with ART registrations and follow-up cards. Two nurses were assigned as supervisors on data collection process.

Checklists, adapted from national pediatric HIV care and treatment guidelines of Ethiopia (CDC, 2012), were used to extract data related to the objectives of the study from mothers and infants HIV chronic care charts. Data collected includes mothers' socio-demography (maternal age, marital status, residence (urban or rural), total number of children, level of education, distance from a health facility and occupation)); time mothers learned their HIV status and whether they were enrolled in and adherent with care; place of infant delivery; PMTCT interventions; infant feeding mode; infants' enrollment age; infants' HIV testing status; infants' age during HIV testing and HIV test result.

Procedures for infant HIV testing in the study health facilities: Dry blood spot (DBS) sample was collected from infants (preferably at 6 weeks age or as early as possible) by ART/PMTCT health care providers at ART/PMTCT clinic of the health facilities. Then samples were properly dried and sent to nearby referral regional laboratory through postal office or courier. The referral regional laboratory run the tests by DNA-PCR machine after running quality control sample and verifying the quality of the test procedure. The test result was immediately communicated to the service provider at the specific health facility via telephone and postal service. Health 
Getahun Bayou et al.,

care providers communicated child test result to caretakers during their visit of chronic care appointment schedule.

\section{Data Quality Management}

Data collectors who are familiar and experienced with registers were assigned to increase for data accuracy and completeness. To decrease biases we selected those with no health profession background. Checklists were adopted considering the content and layout of the records to make ease of accessing necessary information, and pre-checked with records. Data collectors and supervisors were trained on how to use records and fill the checklists. The principal investigator and supervisors checked all data from each health facilities for completeness, accuracy, and consistency immediately following data collection.

\section{Data Processing and Analysis}

Data were entered into Epi-data version 3.1, cleaned and exported to SPSS version 16 for analysis. Descriptive statistics (simple frequency tables, graphs and charts) was used to summarize data. Odds ratio with $95 \%$ confidence interval was used to assess the presence and degree of association between dependent and independent variables. A p-value of less than 0.05 was considered statistically significant. Moreover, for variables with $p$-value less than 0.25 in bivariate analyses, multivariate logistic regression analysis was carried out to control for possible confounding effects and to assess the separate effect of variables. In addition, collinearity diagnostics of variables were carried out and ensured for the absence of multicollinearity among independent variables by considering tolerance value of less than 0.1
Sci. Technol. Arts Res. J., April-June 2015, 4(2): 149-156

or variance inflation rates (VIF) of greater than 10 as indicator for significant multicollinearity. Goodness of model fitness was also checked by the Likelihood ratio test and Omnibus test.

\section{Ethical Considerations}

Ethical clearance was obtained from Jimma University, College of Public Health and Medical Sciences ethical committee. Permission from Zonal and Woreda Health offices and health facilities' managers were also obtained. Names or identification number of HIV exposed infants and their mothers were not included in the data extraction checklists to ensure confidentiality.

\section{RESULTS}

Socio-demographic characteristics of study population Among 349 HIV exposed infants and young children recruited into the study, 180 (51.6\%) and $169(48.4 \%)$ were males and females respectively. The mean age of HIV exposed infants and young children was $10.1( \pm 4.5)$ months.

Of the 349 HIV exposed infants and young children, $342(98.0 \%)$ and $7(2.0 \%)$ were taken care by their mothers, and fathers and/or other guardian (mothers' friend, grandmother and blood relative), respectively. The mean age of the mothers was $28( \pm 5.4)$ years and in average each mother has 2 children. About two third $(67.9 \%)$ of the mothers were urban dwellers, $68.5 \%$ live within 10 kilometers of health facilities, $139(39.8 \%)$ did not attend formal education and 292 (83.7\%) were married (Table 1).

Table 1: Socio-demographic characteristics of HIV exposed infants and their mothers, Western Oromia Region, Ethiopia 2014.

\begin{tabular}{llcc}
\hline \multirow{2}{*}{ Variables $(\mathbf{n}=\mathbf{3 4 9})$} & \multicolumn{2}{c}{ Frequency } \\
\cline { 3 - 4 } & Male & Number & Percent \\
\hline \multirow{2}{*}{ Sex of the infant } & Female & 180 & 51.6 \\
& Mother & 169 & 48.4 \\
\hline \multirow{2}{*}{ Caretaker relation to infant/child } & Father or other guardian & 7 & 98.0 \\
& $15-24$ & 83 & 23.8 \\
\hline \multirow{2}{*}{ Age of mother (years) } & $25-34$ & 214 & 61.3 \\
& $>=35$ & 52 & 14.9 \\
\hline \multirow{2}{*}{ Mother residence } & Urban & 237 & 67.9 \\
& Rural & 112 & 32.1 \\
\hline \multirow{2}{*}{ Mother educational status } & No education/illiterate & 139 & 39.8 \\
& Primary School & 135 & 38.7 \\
& Secondary and above & 75 & 21.5 \\
\hline \multirow{2}{*}{ Marital status } & Married & 292 & 83.7 \\
& Single & 17 & 4.9 \\
\multirow{2}{*}{ Mother employment } & Divorced or widowed & 40 & 11.5 \\
\hline \multirow{2}{*}{ Distance from health facility } & Employed & 18 & 5.2 \\
& Not employed & 331 & 94.8 \\
\hline
\end{tabular}

HIV Chronic Care Follow-Up and PMTCT Interventions

Table 2 summarizes HIV chronic care follow-up, and PMTCT interventions of mothers and infants. Two hundred fifty $(71.6 \%), 75(21.5 \%)$ and $24(6.9 \%)$ of $\mathrm{HEI}$ mothers had known their HIV sero-status before pregnancy, during pregnancy, and during or after delivery respectively. Almost all mothers, 346 (99.1\%) have been following ART chronic care service since their enrollment About $85 \%$ of mothers had disclosed their HIV sero-status with majority $(80.5 \%)$ of them did it to their male partners. Three in five $(60.2 \%)$ mothers of $\mathrm{HEI}$ were linked to mother support group at health facility. Regarding place of 
Getahun Bayou et al.,

delivery, $84.5 \%$ and $15.5 \%$ of mothers gave birth at health institutions and home, respectively. The mean enrolment age of infants to $\mathrm{HEl}$ care was 2 months with minimum and maximum ages at birth and 14 months consequently.
Sci. Technol. Arts Res. J., April-June 2015, 4(2): 149-156

Regarding PMTCT interventions and infant feeding, $91.1 \%$ of $\mathrm{HEl}$ had received ARV prophylaxis and exclusive breast feeding was the most common (98\%) reported mode of infant feeding.

Table 2: HIV chronic care follow-up and PMTCT interventions of mothers and infants, Western Oromia Region, Ethiopia 2014

\begin{tabular}{llcc}
\hline \multirow{2}{*}{ Variables } & & \multicolumn{2}{c}{ Frequency } \\
\cline { 3 - 4 } Period mother heard her sero status $(\mathrm{N}=349)$ & Number & Percent \\
& During pregnancy & 250 & 71.6 \\
& During or after delivery & 75 & 21.5 \\
\multirow{2}{*}{ Mother currently in care $(\mathrm{N}=349)$} & Yes & 24 & 6.9 \\
\hline \multirow{2}{*}{ Mother disclosure HIV status (N=349) } & No & 346 & 99.1 \\
& Yes & 3 & 0.9 \\
\hline \multirow{2}{*}{ To whom disclose Sero status (N=327) } & No & 327 & 93.7 \\
& Mother & 22 & 6.3 \\
\hline \multirow{2}{*}{ Adherence of mother(N=349) } & other relative & 281 & 80.5 \\
& Good & 10 & 2.9 \\
\multirow{2}{*}{ Mother support group linked with(N=349) } & Fair & 36 & 10.3 \\
\hline \multirow{2}{*}{ Enrollment age of the infant(N=349) } & Poor & 316 & 90.5 \\
& Yes & 20 & 5.7 \\
\multirow{2}{*}{ Place of infant delivery(N=349) } & At birth to 6 weeks & 13 & 3.7 \\
\hline \multirow{2}{*}{ Mother received PMTCT interventions(N=349) } & Greater than 6 weeks & 210 & 60.2 \\
& No & 139 & 39.8 \\
\hline \multirow{2}{*}{ Infant received PMTCT interventions(N=349) } & Yes & 295 & 84.5 \\
& No & 54 & 15.5 \\
\hline \multirow{2}{*}{ Mode of infant feeding(N=349) } & Exclusive breast feeding $(6 \mathrm{~m})$ & 342 & 98.0 \\
& Replacement (formula) & 4 & 1.1 \\
& Mixed feeding & 3 & 0.9 \\
\hline
\end{tabular}

HIV Exposed Infants and Young Children HIV Testing

The proportion of HIV testing among HIV exposed infants and young children was $83.7 \%$ with the median testing age of 6 weeks. Among tested infants and young children $53.1 \%$ and $46.9 \%$ were male and female, respectively. Gender disaggregated HIV testing proportions were $86.1 \%$ and $81.1 \%$ for male and female infants, respectively. From $281(96.2 \%)$ samples whose their DNA-PCR results returned from testing facility (referral laboratory) to their respective health care facilities, $5.3 \%$ were found HIV positive (Table 3).

Table 3: HIV exposed infants and young children HIV testing, Western Oromia Region, Ethiopia 2014

\begin{tabular}{cccc}
\hline \multirow{2}{*}{ Variables } & & \multicolumn{2}{c}{ Frequency } \\
\cline { 3 - 4 } & & Number & Percent \\
\hline \multirow{2}{*}{ Infant tested (DNA-PCR) $(\mathrm{N}=349)$} & Yes & 292 & 83.7 \\
& No & 57 & 16.3 \\
\hline \multirow{2}{*}{ Test result received(N=292) } & Yes & 281 & 96.2 \\
& Pending & 10 & 3.4 \\
& No & 1 & 0.3 \\
\hline \multirow{2}{*}{ Infants HIV test results (=281) } & Positive & 15 & 5.3 \\
& Negative & 266 & 94.7 \\
\hline
\end{tabular}

Factors Associated with Testing of HIV Exposed Infants and Young Children

In the bivariate analysis (table 4), mother residence, maternal educational level, number of live children a mother has, mother's HIV sero-status disclosure, presence of mother support group at facility, mother and infant PMTCT interventions, place of delivery, and early age of infant enrollment were found significant predictors for testing of HIV exposed infants and young children.
Table 5 shows multivariate logistic regression analyses of factors associated with testing of HIV exposed infants and young children. Mothers' residence, number of live children the mother has, mother's HIV sero-status disclosure, presence of mother support group at health facility, and early age enrollment of infant to care were independent significant predictor for testing of HIV exposed infants and young children. 
Table 4: Bivariate logistic regression analyses of factors associated with testing of HIV exposed infants and young children, Western Oromia Region, Ethiopia 2014

\begin{tabular}{|c|c|c|c|c|c|}
\hline \multirow{2}{*}{\multicolumn{2}{|c|}{ Factors $(\mathrm{N}=349)$}} & \multicolumn{2}{|c|}{ Infant tested for DNA PCR } & \multirow[b]{2}{*}{ OR $(95 \% \mathrm{Cl})$} & \multirow[b]{2}{*}{$P$ value } \\
\hline & & $\begin{array}{c}\text { Yes } \\
\text { Number (\%) }\end{array}$ & $\begin{array}{c}\text { No } \\
\text { Number (\%) }\end{array}$ & & \\
\hline \multirow{2}{*}{ Sex of the infants } & Male & $155(53.1)$ & $25(46.9)$ & \multirow{2}{*}{$\begin{array}{c}1.45(0.82-2.56) \\
1.00\end{array}$} & \multirow{2}{*}{0.20} \\
\hline & Female & $137(46.9)$ & $32(56.1)$ & & \\
\hline \multirow{2}{*}{ Relation to $\mathrm{HEI}$} & Mother & $286(83.6)$ & $56(16.4)$ & \multirow{2}{*}{$\begin{array}{c}0.85(0.10-7.21) \\
1.00 \\
\end{array}$} & \multirow{2}{*}{0.80} \\
\hline & Other, guardian & $6(85.7)$ & $1(14.3)$ & & \\
\hline \multirow{2}{*}{ Residence } & Urban & $209(88.2)$ & $28(11.8)$ & \multirow{2}{*}{$\begin{array}{c}2.61(1.46-4.65) \\
1.00 \\
\end{array}$} & \multirow{2}{*}{0.001} \\
\hline & Rural & $83(74.1)$ & $29(25.9)$ & & \\
\hline \multirow{3}{*}{ Marital status } & Married & $247(84.6)$ & $45(15.4)$ & 1.00 & \multirow{3}{*}{0.28} \\
\hline & Single & $15(88.2)$ & $2(11.8)$ & $1.37(0.30-6.18)$ & \\
\hline & Divorced or Widowed & $30(75.0)$ & $10(25.0)$ & $0.55(0.25-1.20)$ & \\
\hline \multirow{3}{*}{ Educational status } & No formal education & $109(78.4)$ & $30(21.6)$ & 1.00 & \multirow{3}{*}{0.02} \\
\hline & Primary & $112(83.0)$ & $23(17.0)$ & $1.34(0.73-2.45)$ & \\
\hline & Secondary \& above & $71(94.7)$ & $4(5.3)$ & $4.89(1.65-14.46)$ & \\
\hline \multirow{2}{*}{ Distance from Health facility } & $<10 \mathrm{~km}$ & $204(85.4)$ & $35(14.6)$ & $1.46(0.81-2.63)$ & \multirow{2}{*}{0.20} \\
\hline & $>=10 \mathrm{~km}$ & $88(80.0 \%)$ & $22(20.0 \%)$ & 1.00 & \\
\hline \multirow{3}{*}{ HEI mother age } & 15- 24 & $70(84.3 \%)$ & $13(15.7 \%)$ & $1.13(0.44-2.86)$ & \multirow[t]{3}{*}{0.97} \\
\hline & $25-34$ & $179(83.6 \%)$ & $35(16.4 \%)$ & $1.07(0.48-2.39)$ & \\
\hline & $>=35$ & $43(82.7 \%)$ & $9(17.3 \%)$ & 1.00 & \\
\hline \multirow{3}{*}{ Occupational status } & Employed & $18(100 \%)$ & $0(0 \%)$ & \multirow{3}{*}{$\begin{array}{c}3.36 \mathrm{E} 8 \\
1.00\end{array}$} & \multirow{3}{*}{1.00} \\
\hline & Not employed & $274(82.8 \%)$ & $57(17.2 \%)$ & & \\
\hline & 4 and above & $37(67.3 \%)$ & $18(32.7 \%)$ & & \\
\hline \multirow{3}{*}{$\begin{array}{l}\text { Time mother heard } \\
\text { of her sero-status }\end{array}$} & Before pregnancy & $213(85.2)$ & $37(14.8)$ & $2.88(1.15-7.21)$ & \\
\hline & During pregnancy & $63(84.0)$ & $12(16.0)$ & $2.63(0.92-7.50)$ & 0.02 \\
\hline & During or after delivery & $16(66.7)$ & $8(33.3)$ & 1.00 & \\
\hline & Yes & $291(84.1)$ & $55(14.9)$ & $10.58(0.94-118.73)$ & \\
\hline Mother in chronic care & No & $1(33.3)$ & $2(66.7)$ & 1.00 & 0.06 \\
\hline & Yes & $279(85.3)$ & $48(14.7)$ & $4.02(1.63-9.93)$ & \\
\hline Mother HIV disclosure status & No & $13(59.1)$ & $9(40.9)$ & 1.00 & 0.003 \\
\hline Mother support group & Yes & $200(95.2)$ & $10(4.8)$ & $10.22(4.94-21.11)$ & \\
\hline linked with & No & $92(66.2)$ & $47(33.8)$ & 1.00 & 0.00 \\
\hline Mother PMTC ${ }^{*}$ intenentions & Yes & $287(84.4)$ & $53(15.6)$ & $4.33(1.13-16.66)$ & 0.03 \\
\hline Mother PMICI Interventions & No & $5(55.6)$ & $4(44.4)$ & 1.00 & \\
\hline Place of infant delivery & Health institution & $262(88.8)$ & $33(11.2)$ & $6.35(3.32-12.14)$ & \\
\hline & Home & $30(55.6)$ & $24(44.4)$ & 1.00 & 0.00 \\
\hline Type of facilities infants & Hospitals & $125(85.6)$ & $21(14.4)$ & $1.28(0.71-2.30)$ & 0.40 \\
\hline enrolled & Health centers & $167(82.3)$ & $36(17.7)$ & 1.00 & 0.40 \\
\hline Infant recrived PMTCT* & Yes & $274(86.2)$ & $44(13.8)$ & $4.50(2.06-9.82)$ & Oחم 0 \\
\hline Infant received PMTCT & No & $18(58.1)$ & $13(41.9)$ & 1.00 & 0.00 \\
\hline & At birth to 2 months & $263(89.2)$ & $32(10.8)$ & $7.09(3.70-13.55)$ & Oחم: \\
\hline Intant enrollment age & Greater than 2 months & $29(53.7)$ & $25(46.3)$ & 1.00 & 0.00 \\
\hline & $\begin{array}{l}\text { Exclusive breastfeeding } \\
\text { for } 6 w k\end{array}$ & $286(83.6)$ & $56(16.4)$ & 1.00 & \\
\hline Infant feeding mode & $\begin{array}{l}\text { Replacement or } \\
\text { mixed feeding }\end{array}$ & $6(85.7)$ & $1(14.3)$ & $0.85(0.10-7.21)$ & 0.88 \\
\hline
\end{tabular}

${ }^{*}$ PMTCT: Prevention of mother to child transmission

Utilization of infants HIV testing service was higher among urban dweller mothers when compared to their rural counter parts $[\mathrm{AOR}=2.92,95 \% \mathrm{Cl}(1.15-7.40)]$. Mothers who has few (1-3) number of live children are also more likely to utilize infants HIV testing service when compared to mothers having relatively high ( $>=4)$ number of live children [AOR=3.37, 95\% Cl (1.38-8.22)], and mothers who disclose their sero-status to their partner or to others are more likely to bring their infants for HIV testing when compared to mothers who did not do so
[AOR= 3.29, 95\% Cl (1.05-10.29)].Utilization of infant HIV testing service was also higher among mothers attending health facilities having mother support group as compared to those attending health facilities without mother support group [AOR= 6.55, 95\% Cl $(2.88-$ 14.90)]. In addition, rate of infants HIV testing was higher among infants enrolled to care at their earlier age (birth to 2 months) when compared to those infants enrolled at their late age (greater than 2 months) $[A O R=4.52,95 \%$ Cl (2.00-10.27)]. 
Table 5: Multivariate logistic regression analyses of factors associated with testing of HIV exposed infants and young children, Western Oromia Region, Ethiopia 2014

\begin{tabular}{|c|c|c|c|c|c|c|}
\hline \multirow{2}{*}{ Factors $(\mathrm{N}=349)$} & \multicolumn{2}{|c|}{ HIV testing } & \multirow{2}{*}{ COR $(95 \% \mathrm{Cl})$} & \multirow{2}{*}{$P$ Value } & \multirow{2}{*}{ AOR $(95 \% \mathrm{Cl})$} & \multirow{2}{*}{$P$ Value } \\
\hline & Yes (\%) & No $(\%)$ & & & & \\
\hline \multicolumn{7}{|l|}{ Residence } \\
\hline Urban & $209(88.2)$ & $28(11.8)$ & \multirow{2}{*}{$\begin{array}{c}2.61(1.46-4.65) \\
1.0\end{array}$} & \multirow{2}{*}{0.001} & $2.92(1.15-7.40)$ & \multirow{2}{*}{0.02} \\
\hline Rural & $83(74.1)$ & $29(25.9)$ & & & 1.00 & \\
\hline \multicolumn{7}{|l|}{ Educational status } \\
\hline No formal education & $109(78.4)$ & $30(21.6)$ & \multirow{3}{*}{$\begin{array}{c}1.00 \\
1.34(0.73-2.45) \\
4.89(1.65-14.46)\end{array}$} & \multirow{3}{*}{0.01} & 1.00 & \multirow{3}{*}{0.67} \\
\hline Primary & $112(83.0)$ & $23(17.0)$ & & & $1.02(0.46-2.23)$ & \\
\hline Secondary \& above & $71(94.7)$ & $4(5.3)$ & & & $1.76(0.49-6.38)$ & \\
\hline \multicolumn{7}{|c|}{ Distance from Health facility } \\
\hline$<10 \mathrm{~km}$ & $204(85.4)$ & $35(14.6)$ & \multirow{2}{*}{$\begin{array}{c}1.46(0.81-2.63) \\
1.00\end{array}$} & \multirow{2}{*}{0.20} & $0.50(0.20-1.26)$ & \multirow{2}{*}{0.14} \\
\hline$>=10 \mathrm{~km}$ & $88(80.0)$ & $22(20.0)$ & & & 1.00 & \\
\hline \multicolumn{7}{|l|}{ Number of live children } \\
\hline 1 to 3 & $255(86.7)$ & $39(13.3)$ & \multirow{2}{*}{$\begin{array}{c}3.18(1.65-6.13) \\
1.00\end{array}$} & \multirow{2}{*}{0.00} & $3.37(1.38-8.22)$ & \multirow{2}{*}{0.01} \\
\hline 4 and above & $37(67.3)$ & $18(32.7)$ & & & 1.00 & \\
\hline \multicolumn{7}{|c|}{ Time mother heard her sero-status } \\
\hline Before pregnancy & $213(85.2)$ & $37(14.8)$ & $2.88(1.15-7.21)$ & \multirow{3}{*}{0.08} & $1.34(0.36-5.06)$ & \multirow{3}{*}{0.67} \\
\hline During pregnancy & $63(84.0)$ & $12(16.0)$ & $2.63(0.92-7.50)$ & & $0.76(0.17-3.46)$ & \\
\hline During /after delivery & $16(66.7)$ & $8(33.3)$ & 1.00 & & 1.00 & \\
\hline \multicolumn{7}{|l|}{ Mother currently in care } \\
\hline Yes & $291(84.1)$ & $55(14.9)$ & $10.58(0.94-118.73)$ & & $7.06(0.16-309.74)$ & \\
\hline No & $1(33.3)$ & $2(66.7)$ & 1.00 & 0.06 & 1.00 & 0.31 \\
\hline Mother disclosure HIV s & & & & & & \\
\hline Yes & $279(85.3)$ & $48(14.7)$ & $4.02(1.63-9.93)$ & & $3.29(1.05-10.29)$ & \\
\hline No & $13(59.1)$ & $9(40.9)$ & 1.00 & 0.003 & 1.00 & 0.04 \\
\hline Mother support group $p$ & & & & & & \\
\hline Yes & $200(95.2)$ & $10(4.8)$ & $10.22(4.94-21.11)$ & 0.00 & $6.55(2.88-14.90)$ & \\
\hline No & $92(66.2)$ & $47(33.8)$ & 1.00 & & 1.00 & 0.00 \\
\hline Mother PMTCT* & & & & & & \\
\hline Yes & $287(84.4)$ & $53(15.6)$ & $4.33(1.13-16.66)$ & & $0.41(0.04-4.69)$ & \\
\hline No & $5(55.6)$ & $4(44.4)$ & 1.00 & 0.03 & 1.00 & 0.47 \\
\hline Place of infant delivery & & & & & & \\
\hline Health institution & $262(88.8)$ & $33(11.2)$ & $6.35(3.32-12.14)$ & & $1.80(0.71-4.54)$ & \\
\hline Home & $30(55.6)$ & $24(44.4)$ & 1.00 & 0.00 & 1.00 & 0.22 \\
\hline Infant received prophyla & & & & & & \\
\hline Yes & $274(86.2)$ & $44(13.8)$ & $4.50(2.06-9.82)$ & & $3.34(0.93-12.02)$ & \\
\hline No & $18(58.1)$ & $13(41.9)$ & 1.00 & 0.00 & 1.00 & 0.07 \\
\hline Infant enrollment age & & & & & & \\
\hline At birth to 2 months & 263(89.2) & $32(10.8)$ & $7.09(3.70-13.55)$ & & $4.52(2.00-10.27)$ & \\
\hline Greater than 2 months & $29(53.7)$ & $25(46.3)$ & 1.00 & 0.00 & 1.00 & \\
\hline
\end{tabular}

*PMTCT: Prevention of mother to child transmission

\section{DISCUSSION}

The main objective of early infant diagnosis of HIV infection is to detect HIV infection in infants and young children that allows health care providers to offer optimal care and treatment of HIV infected children, assists in decision making on infant feeding, and avoids needless stress in mothers and families. To achieve this objective the service has to be available and properly utilized by caretakers of $\mathrm{HEI}$ at health facility level (WHO, 2010). This study aimed to determine the magnitude of HIV testing and factors associated with its utilization using the available DBS, DNA PCR method among HIV exposed infants and young children in Western Oromia Region, Ethiopia.

In this study, $83.7 \%$ of HIV exposed infants aged 4 weeks to 18 months among all enrolled at healthcare facilities of Western Oromia region were tested. The study finding is nearly in agreement with what was reported in Tanzania which was $87 \%$ (Gregory, 2012) but higher than that reported from Malawi (71.6\%) (Dube et al., 2012), Kenya (67\%) (Ciaranello et al., 2011) and Zambia (10\%) (Torpey et al., 2012). The finding is also higher than the report from study conducted in Addis Ababa, Ethiopia, where $52 \%$ of HIV exposed children tested (Alemnesh et al., 2011), and national HIV exposed infant testing estimates reported by WHO-UNICEF (19\%) and CDCEthiopia (45\%) (UNAIDS, UNICEF, WHO, 2013; CDC Ethiopia, 2012). This result showed that utilization of EID of HIV infection in the study area was high relative to previous studies conducted in different countries. Integration of EID in to expanded program of immunization (EPI) services, decentralization of the services to primary health care, expanded testing referral laboratory and support from non-governmental organizations (NGO) partners may explain the high utilization of the service in health facilities in our study 
Getahun Bayou et al.,

area. The other possible explanation for this higher finding might also be time (recent time) of the study; because awareness of mothers increases through time. Even though the coverage was good $(83.7 \%)$, still $16.3 \%$ of HIV exposed infants and young children were not tested for HIV, which is against WHO recommendations which asserted that all HIV exposed infants should be tested at their early age 4-6 weeks (WHO, 2010). Therefore, more efforts are needed to maximize identification and testing of HIV exposed infants by strengthening EID of HIV infection testing with PMTCT services and other potential entry points.

The current Ethiopian national algorithm for EID of HIV infection recommends testing of HIV exposed infants at the age of 4-6 weeks or as early as possible thereafter (Federal HIVIAIDS Prevention and Control Office Federal Ministry of Health (2007). In this study, the median age of HIV testing was 6 weeks, which is consistent with WHO recommendations (WHO, 2010). But it is in contrast to findings from Tanzania (4 weeks) (Gregory, 2012) and Mozambique (5 months) (Rebecca et al., 2011). The median age of EID testing found in this study might have been contributed by more sensitization through mother counseling, increased awareness on EID of HIV infection and integrating the appointment for DBS sample collection with 6 weeks EPI service.

The study identified some factors which were associated with HIV testing among HIV exposed infants and young children.

This study showed that urban dwelling mothers were more likely to utilize EID service when compared to rural residents. This difference might be due to the fact that urban mothers have better access to health services and have information about infants early HIV testing than their rural counterparts.

Mothers who have less number of live children were also more likely to utilize EID of HIV infection when compared to mothers who have more number of live children. This is similar to findings of a study conducted in Addis Ababa, Ethiopia, where number of children mother possess was significantly associated with HIV testing of HIV exposed infants and young children (Matinhure, 2013). This service utilization difference might be due to the fact that mothers with relatively high number of live children may be over burdened by giving care to children and may give relatively less attention to HIV exposed infant testing service when compared to mothers with few number of live children. The other possible explanation might be that mothers with few live children may be more careful of their infants and seeking institutional care when compared to mothers with relatively high number of live children.

Mothers' disclosure of HIV sero-status was also found to be one predictor for early HIV testing of HIV exposed infants. Mothers who disclosed their HIV sero- status were more likely to utilize EID services than those who did not, which is similar findings with a study conducted in Kenya (Hassan et al., 2012). Mothers who disclose their HIV sero-status can bring their infants to health service for HIV testing and counseling without fear of partner/relatives since they disclosed their status when compared to mothers who did not disclose their serostatus, might be possible explanation for this difference.
Sci. Technol. Arts Res. J., April-June 2015, 4(2): 149-156

Linkage of mothers to mother support group at health facility were also significantly associated with HIV testing of exposed infants and young children. Similarly, a study conducted in Kenya revealed that the presence of the psychosocial support group was significantly associated with HIV testing of HEI (Hassan et al., 2012). This difference might arose because mothers who are linked to health facilities with available mother support group may get adequate counseling and information about early HIV testing of HIV exposed infants when compared to mothers linked to health facilities without mother support group.

Early enrollment of HIV exposed infants and young children to care were also found as predictor for utilization of EID service. This might be due to children who are enrolled to care in their late age may be antibody tested because of their older age.

The study was conducted in 27 health facilities with different recruitments and working practices (hospitals and health centers).This enables it to reflect on the diversity of practical management of EID of HIV infection in a diverse population living in Western Oromia region. And this can be taken as the strength of the study. On the other hand the study has some limitations as well: (1) it used secondary data, (2) it was carried in a health facility levels and (3) it included participants who came to the clinic for services. Thus it may not represent those who are potentially in the community and had no opportunity to reach the health care facility for services. The other limitation is that health care related factors for utilization of EID service were not assessed.

\section{CONCLUSIONS}

Utilization of early infant diagnosis of HIV was relatively high in health institutions of Western Oromia Region. The study demonstrated that there is difference in utilization of early HIV diagnosis service of HIV exposed infants in place of residence, number of children mother have, HIV sero-status disclosure status of mothers, availability of mother support groups, and enrollment age of infants to care. Hence, there is need to provide adequate counseling of mothers on benefits of HIV serostatus disclosure to their partner, family planning and early enrollments of infants to care with an eye on rural attendants. Also further researches using primary data by including all possible potential factors of EID service utilization are recommended.

\section{Acknowledgements}

We would like to thank Zonal Health Offices (East Wollega, Horo Guduru Wollega, West Wollega and Kelem Wollega Zonal health offices), Woreda Health Offices and Health facility managers who facilitated conditions to conduct this assessment. Our special gratitude also goes to the teaching and supporting staff of the Department of Epidemiology and Biostatistics, Jimma University for their support in providing different literature. Finally, we would like to thank data collectors, the supervisors and study subjects for their invaluable input to this thesis work

\section{Conflict of Interest}

The authors declared that no competing interests exist 


\section{REFERENCES}

Alemnesh, H., Mitike, M., Karen, M., and Anne, N. (2011). Applying the theory of planned behaviour to explain HIV testing in antenatal settings in Addis Ababa - a cohort study. BMC Health Services Research 1:196.

CDC Ethiopia (2012) Centre for Disease control and Prevention Report for 2012. Atlanata. Available: http:// www.cdc.gov/globalhealth. Accessed 26 December 2013.

Ciaranello, A., Park, J., Ramirez-Avila, L., Freedberg, K., Walensky, R. and Leroy, V. (2011). Early infant HIV-1 diagnosis programs in resource limited settings: opportunities for improved outcomes and more costeffective interventions. BMC Medicine 9: 59.

Dube, Q., Dow, A., Chirambo, C., Lebov, J., Tenthani, L., Moore, M., Heyderman, R. and Van Rie, A. (2012). Implementing early infant diagnosis of HIV infection at the primary care level: experiences and challenges in Malawi. Bull world Organ 90: 699-704.

Federal HIVIAIDS Prevention and Control Office Federal Ministry of Health (2007) Guidelines for Pediatric HIV Care and Treatment in Ethiopia. 3rd edition, Addis Ababa. Available: http://www.ilo.org/wcmsp5/groups/.../---ed.../--ilo.../wcms 125387.pdf. Accessed on 26 December 2013.

Fonjungo, P., Girma, M., Melaku, Z., Mekonen, T., Tanuri, A., Hailegiorgis, B., Tegbaru, B., Mengistu, Y., Ashenafi, A., Mamo, W., Abreha, T., Tibesso, G., Ramos, A., Ayana, G., Freeman, R., Nkengasong, J., Zewdu, S., Kebede, Y., Abebe, A., Kenyon, T., Messele, T. (2013). Field expansion of DNA polymerase chain reaction for early infant diagnosis of HIV-1: The Ethiopian experience. African Journal of Laboratory Medicine 2(1):31.

Gregory, J. (2012). Utilization of the early infant diagnosis of HIV infection and its associated factors in Coast Region Tanzania. PhD [dissertation]. Tanzania: Muhimbili University. available at http://ihi.eprints.org/1736/1/John Gregory Gamaliel.pdf. accessed on 8/29/2013

Hassan, A., Sakwa, E., Nabwera, H., Taegtmeyer, M., Kimutai, R., Sanders, E., Awuondo, K., Mutinda, M., Molyneux, C., Berkley, J. (2012). Dynamics and constraints of early infant diagnosis of HIV infection in Rural Kenya. AIDS and Behavior 16(1): 5-12.

Joint United Nation Programme on HIV AIDS (2013). Report on the global AIDS epidemic. Geneva. Available: http://www.UNAIDS/JC2502/1/E. Accessed on 7 Dec 2013.

Matinhure, N. (2013). Knowledge, Attitudes and Practices among Parents towards Human Immuno- Deficiency Virus (HIV) Testing and Treatment for Children: The Case of Addis Ababa, Ethiopia. PhD (dissertation). Ethiopia: University of South Africa; Available at: http://uir.unisa.ac.za/bitstream/handle/10500/13048/disser tation matinhure n.pdf?sequence $=1$ Accessed on $1 / 5 / 2014$.

Rebecca, E., Philip, J., Mohsin,. S, Blevins, M., Burlison, J., Davidson, M., Vergara, A., Vermund, S., Moon, T., (2011). Predictors of successful early infant diagnosis of HIV in a rural district hospital in Zambézia, Mozambique. Journal of Acquired Immuno Deficiency Syndrome 56(4): e104-e109. doi:10.1097/QAI.0b013e318207a535.

Torpey, K., Mandala, J., Kasonde, P., Bryan-Mofya, G., Bweupe, M., Mukundu, J., Zimba Ch., Mwale, C., Lumano, H., Welsh, M. (2012). Analysis of HIV Early Infant Diagnosis Data to Estimate Rates of Perinatal HIV Transmission in Zambia. PLoS ONE 7(8): e42859. doi:10.1371/journal.pone.0042859.

UNAIDS, UNICEF, WHO (2013). Global AIDS Response Progress Reporting and UNAIDS HIV and AIDS estimates. Geneva. Available: www.unaids.org/.../unaids/contentassets/documents Accessed on 26 December 2013

WHO (2010). Recommendations on the diagnosis of HIV infection in infants and children. Geneva. Available: http://www.who.int/hiv/pub/pediatric/diagnosis/en/index. html. Accessed on 6 December 2013

World Health Organization (2010) Guidance note on the selection of technology for the early diagnosis of HIV in infants and children. Geneva. Available: www.who.int/hiv/.../EarlydiagnostictestingforHIVVer Final May07.pdf. Accessed on 6 March 2013. 